\title{
WILEY-VCH
}

DOI: 10.1002/((please add manuscript number))

Article type: Communication

\section{pH-Responsive Capsules Engineered from Metal-Phenolic Networks for Anticancer Drug Delivery}

Yuan Ping, Junling Guo, Hirotaka Ejima, Xi Chen, Joseph J. Richardson, Huanli Sun and Frank Caruso*

Dr. Yuan Ping, Junling Guo, Dr. Hirotaka Ejima, Xi Chen, Joseph J. Richardson, Dr. Huanli Sun and Prof. Frank Caruso*

ARC Centre of Excellence in Convergent Bio-Nano Science and Technology, and

Department of Chemical and Biomolecular Engineering, The University of Melbourne, Parkville, Victoria 3010, Australia

E-mail: fcaruso@unimelb.edu.au

Keywords: Templated assembly, hybrid organic-inorganic materials, controlled release, chemotherapeutics, stimuli-responsive, coordination complex

Despite significant advances in diagnosis and therapy over the past 20 years, cancer remains one of the leading causes of death. Patients treated by conventional strategies commonly suffer from frequent relapses and metastases and experience severe side effects shortly after treatment. For example, doxorubicin hydrochloride (DOX), one of the most well-known cytostatic chemotherapeutic agents used in the treatment of a wide variety of cancers is often associated with severe suppression of hematopoiesis, and gastrointestinal and cardiac toxicity when it is administered in vivo directly. ${ }^{[1,2]}$ In order to enhance the therapeutic outcomes and reduce side effects of anticancer drugs, different types of drug carriers, including liposomes, ${ }^{[3]}$ polymeric micelles, ${ }^{[4-6]}$ polymersomes, ${ }^{[7,8]}$ carbon nanotubes, ${ }^{[9,10]}$ mesoporous silica nanoparticles, ${ }^{[11,12]}$ and polymeric nanoparticles ${ }^{[13]}$ have been extensively studied to improve therapeutic outcomes. Hollow polymeric capsules that are engineered through the layer-bylayer (LbL) deposition of polymers onto a sacrificial template have also become of interest for drug delivery due to their controllable physicochemical and biological properties, including a broad suite of capsule materials, tunable size, selective permeability, and stimuli-responsive functionality for controlled release and degradation. ${ }^{[14-17]}$ Effective carriers should be able to 


\section{WILEY-VCH}

encapsulate and release loaded therapeutic agents. To this end, capsules that respond to intracellular stimuli such as $\mathrm{pH}$, temperature, redox potential, and enzymes to initiate cargo release are of particular interest. ${ }^{[18]} \mathrm{pH}$-responsive drug delivery systems have been mostly exploited for triggered drug release at the tumor site and/or inside tumor cells, due to the $\mathrm{pH}$ gradient between tumor tissues ( $\mathrm{pH}$ 5.7-6.8) and extracellular fluids ( $\mathrm{pH} \sim 7.4$ ) as well as the acidic environment inside endosomal ( $\mathrm{pH}$ 5.5-6.0) and lysosomal ( $\mathrm{pH}$ 4.5-5.0) compartments. ${ }^{[19-21]}$

Recently, we introduced one-step assembly of phenolic-based thin films as a rapid and simple alternative technology for template-mediated capsule preparation. ${ }^{[22]}$ We reported that complexation between tannic acid (TA), a polyphenolic ligand, and metal ions, form robust nano-scaled films on various templates, affording hollow, metal-phenolic network (MPN) capsules following template removal. ${ }^{[23,24]}$ Herein, we report the assembly of drug delivery systems that are engineered from these MPN coordination complex films and exhibit controllable pH-dependent degradability and intracellular drug delivery. The preparation of the drug-loaded capsules that incorporate the $\mathrm{pH}$-responsive release mechanism is demonstrated in Scheme 1. As a proof-of-concept, poly(styrene sulfonate) (PSS)-doped calcium carbonate $\left(\mathrm{CaCO}_{3}\right)$ particles were easily prepared by co-precipitation in the presence of $\mathrm{CaCl}_{2}$ and $\mathrm{Na}_{2} \mathrm{CO}_{3} \cdot{ }^{[25]}$ By simply mixing the PSS-doped $\mathrm{CaCO}_{3}$ with DOX, large amounts of DOX could be deposited into the porous interior of the $\mathrm{CaCO}_{3}$ templates. ${ }^{[26,27]}$ Electrostatic interaction, ${ }^{[28]}$ hydrogen boding interaction, ${ }^{[29,30]}$ and hydrophobic interaction ${ }^{[31]}$ stabilize the PSS-DOX complexes. Stable metal-polyphenol coordination films were then rapidly formed around the DOX-deposited $\mathrm{CaCO}_{3}$ templates simply by vortexing $\mathrm{TA}$ and metal ions in $\mathrm{pH}$ 8.0 buffer solution. Monodisperse DOX-loaded MPN capsules were subsequently obtained after dissolution of the template. The fabrication process was carried out in a rapid process with mild condition. As many types of anticancer drugs, such as irinotecan and topotecan 


\section{WILEY-VCH}

(topoisomerase inhibitors), as well as other drugs in combination with anticancer drugs, such as verapamil (a multidrug resistance modulator) possess both benzyl groups and amine groups in their structure (Figure S1), we have also obtained MPN capsules loaded with irinotecan, topotecan or verapamil through this fabrication method (Table S1). By taking advantage of the diverse chelation ability of phenolic materials to form coordination complexes with different metal ions, the DOX-loaded MPN capsules can be functionalized by coordination with manganese $(\mathrm{Mn})$ and gadolinium(Gd) for potential theranostic applications (Figure S2). ${ }^{[24]}$ Due to the presence of the large excess of reactive phenolic hydroxyl groups on the capsule surface, the drug-loaded MPN capsules are also expected to undergo a variety of surface modifications through catechol-thiol reaction, ${ }^{[32,33]}$ metal coordination, ${ }^{[34]}$ and boronic acid-catechol complexation $^{[35]}$ for more specific applications.

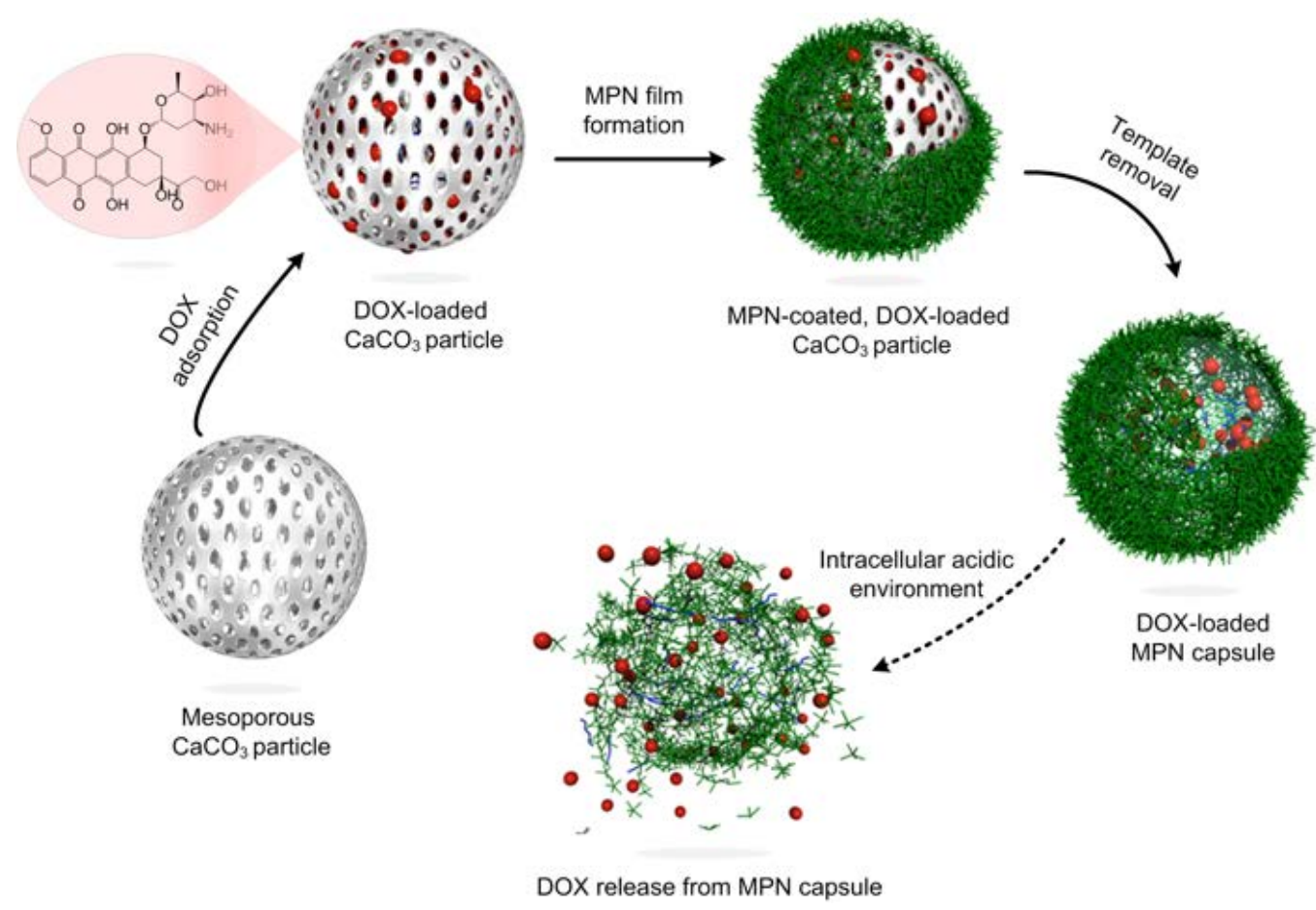

Scheme 1. Schematic of the fabrication process of DOX-loaded MPN capsules and release mechanism of DOX from MPN capsules.

The morphology of the DOX-loaded $\mathrm{Al}^{\mathrm{III}}$-TA capsules (DOX-Al ${ }^{\mathrm{III}}$-TA) prepared from TA and $\mathrm{Al}^{\mathrm{III}}$ ions with $D=2.5 \mu \mathrm{m}$ templates was first characterized using differential interference 


\section{WILEY-VCH}

contrast (DIC) microscopy, deconvolution microscopy (DM), transmission electron microscopy (TEM) and scanning electron microscopy (SEM). As shown in Figure 1, DIC microscopy indicates that the DOX-Al ${ }^{\mathrm{III}}$-TA capsules were monodisperse and spherical. DM images show that the core of the DOX-Al ${ }^{\mathrm{III}}$-TA capsules has strong, red fluorescence originating from the encapsulated DOX, while the green fluorescence signal originates from the $\mathrm{Al}^{\mathrm{III}}$-TA shell which is labeled with FITC-BSA. The three-dimensional (3D) reconstruction derived from different focal planes further validated the loading of DOX in the $\mathrm{Al}^{\mathrm{III}}$-TA capsules (Figure S3). The encapsulated DOX within the $\mathrm{Al}^{\mathrm{III}}$-TA films was visualized by TEM on ultra-microtomed sections (Figure S4). Furthermore, both SEM and TEM showed that the $\mathrm{Al}^{\mathrm{III}}$-TA capsules were densely loaded with DOX and form a spherical structure even after drying, which is significantly different than the appearance of unloaded hollow MPN capsules. Without DOX, the $\mathrm{Al}^{\mathrm{III}}$-TA capsule shell was observed by DIC microscopy or DM (Figure S5). Both TEM and SEM showed folds and creases, typical features of air-dried, free-standing capsules. Energy dispersive X-ray (EDX) mapping analysis of DOX-Al ${ }^{\mathrm{III}}$-TA capsules demonstrated that the distribution patterns of nitrogen, which is ascribed to the primary amines of DOX, matched well with the distribution patterns of $\mathrm{Al}$ and $\mathrm{O}$ maps (Figure 1e) and high-angle annular dark-field images (HAADF) (Figure S6). The DOX loading capacity was approximately 1.31 pg per capsule, and the drug loading amount could be varied from 0.42 to $1.31 \mathrm{pg} /$ capsule simply by controlling the weight ratio of DOX to $\mathrm{CaCO}_{3}$ template (Figure S7). By using submicron templates, DOX-loaded capsules of $\sim 800 \mathrm{~nm}$ could also be formed (Figure S8). 


\section{WILEY-VCH}
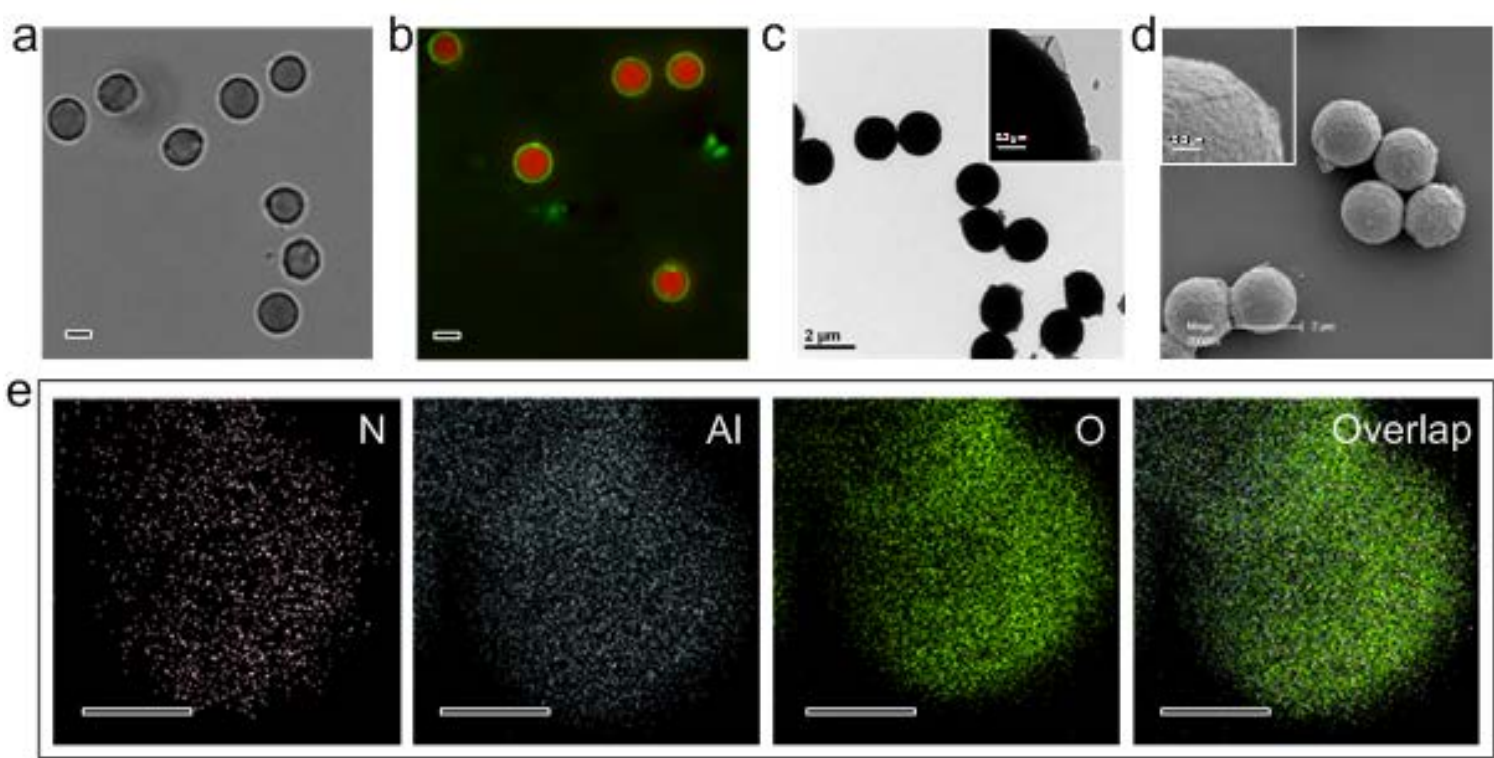

Figure 1. Characterization of DOX-Al ${ }^{\mathrm{III}}$-TA capsules. a) DIC, b) DM, c) TEM, and d) SEM images of DOX-Al ${ }^{\mathrm{III}}$-TA capsules. e) EDX elemental mapping of DOX-Al ${ }^{\mathrm{II}}-\mathrm{TA}$ capsules. Scale bars represent $2 \mu \mathrm{m}$ in a)-d), $0.2 \mu \mathrm{m}$ in the inset of c) and d), and $1 \mu \mathrm{m}$ in e).

The formation of coordination bonds between polyphenols and $\mathrm{Al}^{\mathrm{III}}$ is $\mathrm{pH}$ dependent. ${ }^{[34]}$ Our previous study demonstrated that the capsule film formed from the coordination complex between $\mathrm{Fe}^{\mathrm{III}}$ and TA exhibits $\mathrm{pH}$-dependent disassembly. ${ }^{[23,24]}$ However, the narrow $\mathrm{pH}$ range (3.0 - 4.0) of disassembly has made it difficult to achieve controlled and selective release of therapeutic agents at relevant physiological conditions. Most recently, we observed significant differences in the disassembly kinetics of MPN capsules prepared from different metals in response to acidic conditions. ${ }^{[24]}$ To examine whether the $\mathrm{Al}^{\mathrm{III}}$-TA capsules prepared from $\mathrm{CaCO}_{3}$ template undergo $\mathrm{pH}$-dependent disassembly within a physiologically relevant $\mathrm{pH}$ range, the degradation behavior of $\mathrm{Al}^{\mathrm{III}}$-TA capsules was first studied at $\mathrm{pH}$ 7.4, 6.0 and 5.0, which mimic the environment of extracellular fluid, intracellular endosomes, and lysosomes, respectively. As depicted in Figure 2a, the disassembly of $\mathrm{Al}^{\mathrm{III}}$-TA capsules was highly $\mathrm{pH}$-dependent, and the stability of the capsules generally decreased as the $\mathrm{pH}$ decreased from 7.4 to 5.0. At pH 5.0, the capsules significantly degraded within 48 h, with less than $20 \%$ remaining after $48 \mathrm{~h}$ incubation. At $\mathrm{pH}$ 6.0, the rate of disassembly was similar to that at pH 5.0 within the first $24 \mathrm{~h}$, but became slower from $24 \mathrm{~h}$ to $48 \mathrm{~h}$. In contrast, the 


\section{WILEY-VCH}

$\mathrm{Al}^{\mathrm{III}}$-TA capsules were relatively stable at $\mathrm{pH} 7.4$ compared to $\mathrm{pH} 5.0$ and 6.0, with more than $80 \%$ of the capsules remaining after $48 \mathrm{~h}$. The $\mathrm{pH}$-dependent disassembly of $\mathrm{Al}^{\mathrm{III}}$-TA capsules is likely due to the decreased complex stability with decreasing $\mathrm{pH}^{[34]}$ In view of the major difference in degradation rate between $\mathrm{pH} 7.4$ and 5.0, we further investigated DOX release from DOX-Al ${ }^{\mathrm{III}}$-TA capsules at these $\mathrm{pH}$ conditions. As shown in Figure 2b, DOX$\mathrm{Al}^{\mathrm{III}}$-TA generally exhibited fast release of $\mathrm{DOX}$ at $\mathrm{pH} 5.0$ and an intermediate release rate at $\mathrm{pH} 6.0$, with almost $62 \%$ and $53 \%$ of DOX released from DOX-Al ${ }^{\mathrm{III}}-\mathrm{TA}$ capsules within the first $48 \mathrm{~h}$ at $\mathrm{pH} 5.0$ and $\mathrm{pH}$ 6.0, respectively. At $\mathrm{pH}$ 7.4, less than $30 \%$ of the total DOX was released from the DOX-Al ${ }^{\mathrm{III}}$-TA capsules within $48 \mathrm{~h}$, indicating some leakage of the DOX at extracellular $\mathrm{pH}$ and salt concentrations. The difference in stability at extracellular physiological $\mathrm{pH}$ and intracellular endo/lysosome $\mathrm{pH}$ conditions is favorable for the enhanced intracellular release of cargo when combined with the $\mathrm{pH}$-dependent stability of DOX-Al $\mathrm{II}_{-}^{\mathrm{II}}$ TA capsules. To determine whether the DOX release kinetics are associated with the capsule degradation kinetics, we compared the disassembly and release kinetics between degradable $\mathrm{Al}^{\mathrm{III}}$-TA capsules and relatively stable $\mathrm{Fe}^{\mathrm{III}}$-TA capsules at physiologically relevant $\mathrm{pH}$. As indicated in Figure S9, there is a major difference in degradation rate between $\mathrm{Al}^{\mathrm{III}}$-TA and $\mathrm{Fe}^{\mathrm{III}}$-TA capsules at $\mathrm{pH}$ 5.0, although they are relatively stable at $\mathrm{pH}$ 7.4. The difference in degradation kinetics was directly associated with the release profile of DOX, indicating that DOX release from DOX-Al ${ }^{\mathrm{III}}$-TA capsules is $\mathrm{pH}$-dependent. Therefore, it is clear that the degradation of DOX-Al ${ }^{\mathrm{III}}$-TA capsules plays a major role in the release of DOX at simulated intracellular pH. The permeability of the DOX-Al ${ }^{\mathrm{III}}$-TA capsules (Figure S10) would allow the diffusion of free DOX through their permeable shells, as a result of reduced hydrogen bonding interaction between DOX and $\mathrm{PSS}^{[30]}$ and increased hydrophilicity of $\mathrm{DOX}^{[36]}$ at lower $\mathrm{pH}$. 
a

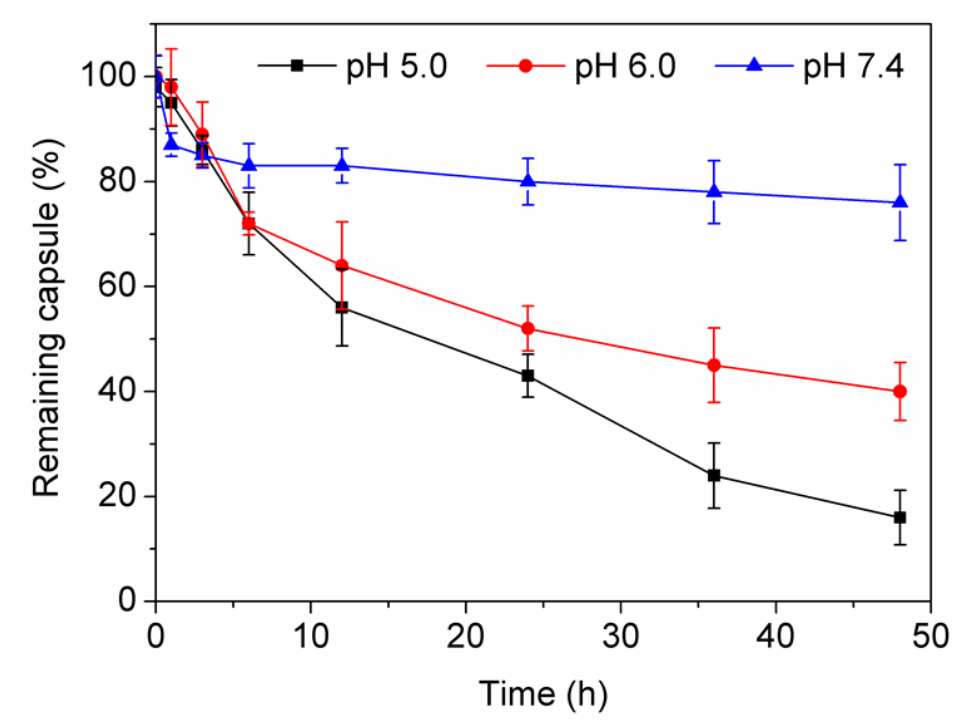

b

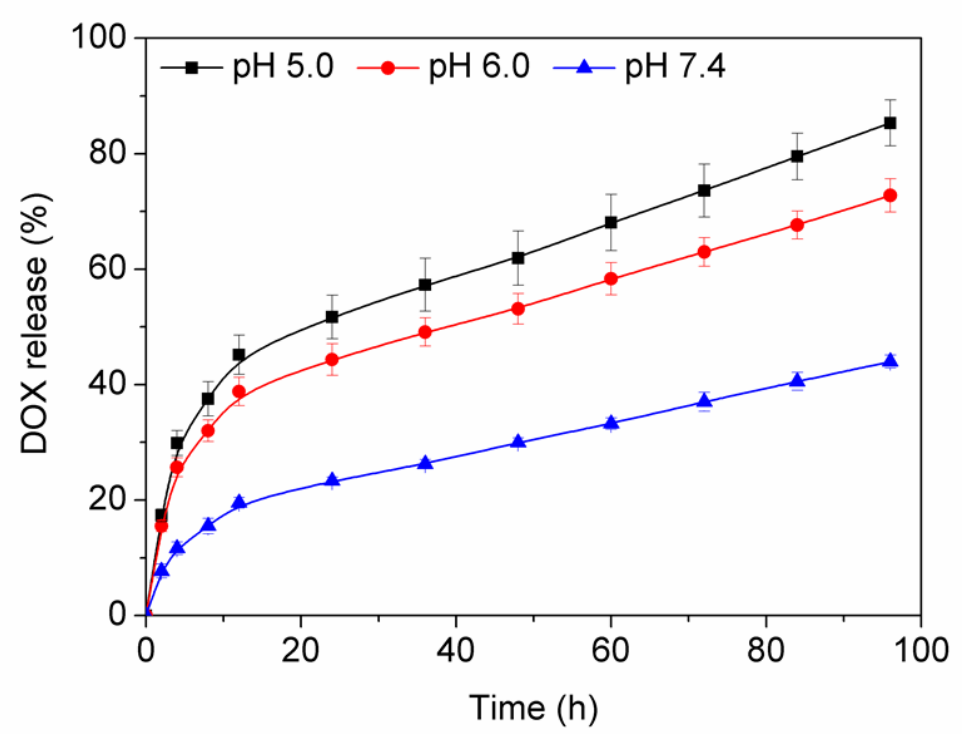

Figure 2. a) Degradation kinetics of $\mathrm{Al}^{\mathrm{III}}$-TA capsules at $\mathrm{pH} 5.0,6.0$, and 7.4, as assessed by flow cytometry. b) Time-dependent release of DOX from DOX-Al ${ }^{\mathrm{III}}-\mathrm{TA}$ capsules at $\mathrm{pH}$ 5.0, 6.0, and 7.4. All data are means $\pm \operatorname{SD}(n=3)$.

To explore whether DOX-Al ${ }^{\mathrm{III}}$-TA capsules could be internalized by cancer cells, intracellular trafficking of capsules and DOX release were visualized. DOX-Al ${ }^{\mathrm{III}}-\mathrm{TA}$ capsules were internalized into both HeLa and MB231 cell lines and accumulated in the periphery of the cell nucleus (Figure 3a, b). The 3D-reconstructed fluorescence images further confirmed that the DOX-Al ${ }^{\mathrm{III}}$-TA capsules were located within the WGA-stained cell membrane (Figure S11). Most importantly, DOX distributed in the nucleus and cytoplasm, suggesting efficient capsule 


\section{WILEY-VCH}

internalization and intracellular DOX release. This also explains the degradation of TA$\mathrm{Al}^{\mathrm{III}}$ capsules mainly occurs in endosomal compartments, where the $\mathrm{pH}$ is low. As a result, the released DOX in the endosomes can readily diffuse into the cytoplasm through the endosomal membrane without endosomal disruption. ${ }^{[37,38]}$ These results prompted us to further explore whether the DOX-Al ${ }^{\mathrm{III}}$-TA capsules could induce effective cytotoxicity and apoptosis in these cancer cells. As both HeLa and MB231 cells are sensitive to DOX treatment, we first examined the cell viability of the treated cells by MTT assays. Figure 4a shows the cell viability as a function of DOX concentration. Both DOX-Al ${ }^{\mathrm{III}}$-TA capsules and free DOX exhibited a dose-dependent cytotoxicity in both cell lines. DOX-Al ${ }^{\mathrm{III}}$-TA capsules were found to be more effective in killing HeLa cells in the range of 0.15 to $1.5 \mu \mathrm{g} / \mathrm{mL}$ when compared to the equivalent concentration of free DOX under the same assay condition. In the case of MB231 cell lines, DOX-Al ${ }^{\mathrm{III}}$-TA capsules showed similar levels of cytotoxicity in the range of $2.9 \times 10^{-3}$ to $15 \mu \mathrm{g} / \mathrm{mL}$ as compared to the equivalent concentration of free DOX. The halfmaximal inhibitory concentration ( $\mathrm{IC}_{50}$ ) estimated from the MTT assay indicates the enhanced cytotoxicity of DOX-Al ${ }^{\mathrm{III}}$-TA capsules to the HeLa cell line from $0.84 \mu \mathrm{g} / \mathrm{mL}$ to $0.20 \mu \mathrm{g} / \mathrm{mL}$ (Table S2). The cytotoxicity of $\mathrm{Al}^{\mathrm{III}}-\mathrm{TA}$ capsules is almost negligible even at a capsule to cell ratio of 500:1. (Figure S12). The apoptosis rate in HeLa and MB231 after the treatment with DOX-Al ${ }^{\mathrm{III}}$-TA capsules or free DOX was also assessed at an equivalent DOX concentration of $1.0 \mu \mathrm{g} / \mathrm{mL}$ at different treatment times. As shown in Figure $\mathbf{4 b}$, the apoptosis rate induced by DOX-Al ${ }^{\mathrm{III}}$-TA capsules reached $\sim 40 \%$ after $48 \mathrm{~h}$ treatment, which was significantly higher than that of DOX-induced apoptosis. In the MB231 cell line, the DOX$\mathrm{Al}^{\mathrm{III}}$-TA capsules showed a comparable ability to induce apoptosis as compared with free DOX. The key mechanism of DOX action is likely to be associated with the activation of p53, which in turn promotes apoptosis of tumor cells. ${ }^{[39,40]}$ Whereas free DOX could passively diffuse into intracellular regions in both tumor cells, the cell type-dependent endocytosis of DOX-Al ${ }^{\mathrm{III}}$-TA capsules resulted in a different level of capsule uptake between MB231 and 


\section{WILEY-VCH}

HeLa cells (Figure S11), which may eventually lead to a different degree of p53 activation.

These results suggest DOX transported by $\mathrm{Al}^{\mathrm{III}}$-TA capsules was able to induce effective apoptosis in cancer cell lines at comparable or even lower DOX concentrations than free DOX, and indicates that DOX-Al ${ }^{\mathrm{III}}$-TA capsules may facilitate intracellular delivery of DOX and thus enhance the therapeutic efficacy.

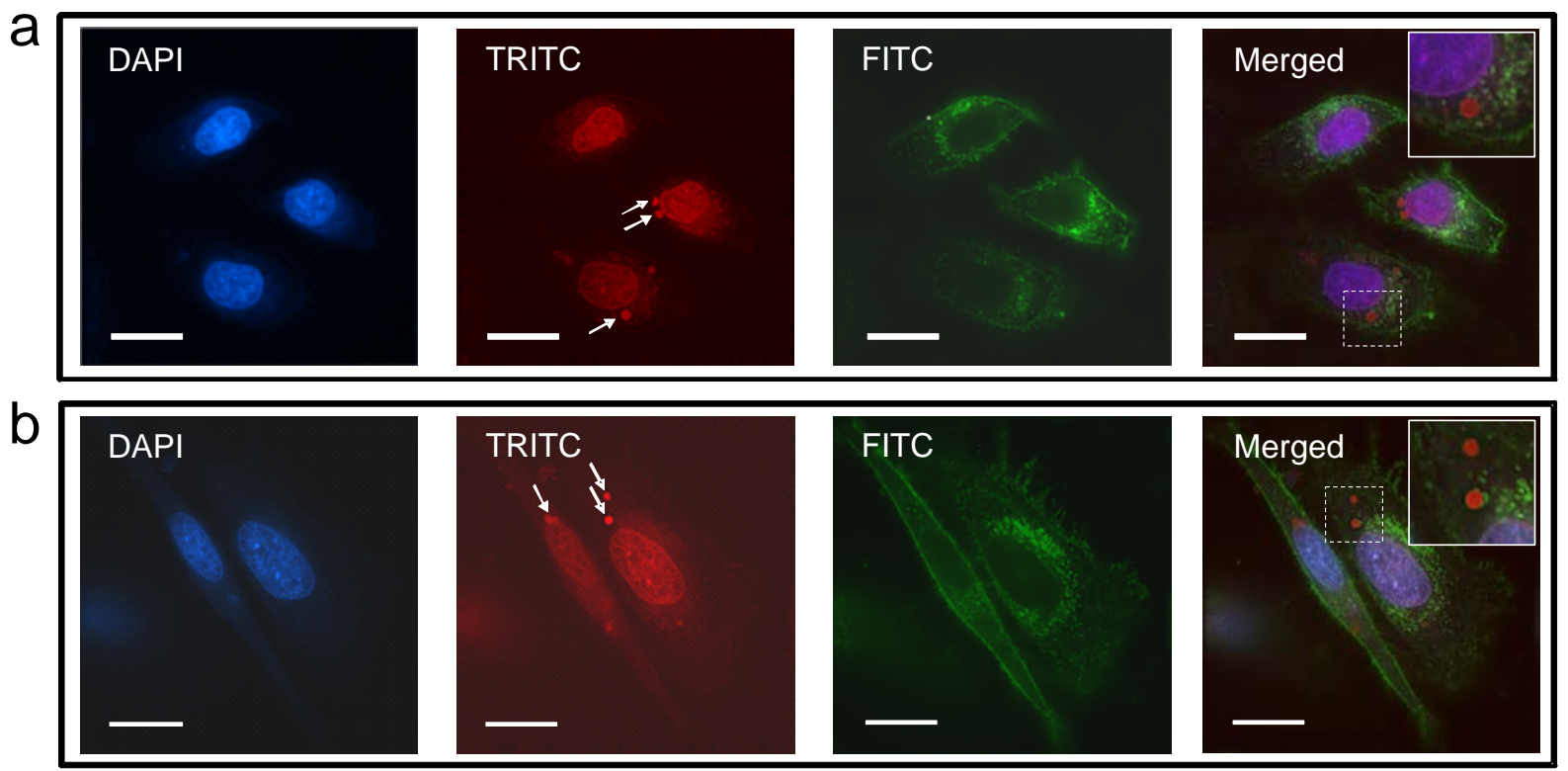

Figure 3. Images of intracellular delivery of DOX-Al ${ }^{\mathrm{III}}-\mathrm{TA}$ capsules in a) MB231 cells and b) HeLa cells, acquired by deconvolution microscopy (DM) with a standard FITC/TRITC/DAPI filter set. HeLa cells were incubated with capsules at a capsule-to-cell ratio of 20:1 for $24 \mathrm{~h}$. The blue nucleus stained with Hoechst 33342 was visualized with the DAPI filter, and green cell membrane stained with wheat germ agglutinin Alexa Fluor ${ }^{\circledR} 488$ was visualized with the FITC filter. The inherent red fluorescence of DOX was observed with the TRITC filter. All scale bars represent $10 \mu \mathrm{m}$.

In conclusion, we have demonstrated that drug-loaded MPN capsules, which are based on the formation of coordination complexes between tannic acid and $\mathrm{Al}^{\mathrm{III}}$ ions, can be assembled and used as pH-responsive carriers for drug loading and intracellular drug release. The MPN capsules exhibited a high drug loading capacity (1.3 pg/capsule of DOX) and pH sensitivity, which give rise to $\mathrm{pH}$-enhanced drug release kinetics and enhanced effectiveness in killing HeLa cells with $\mathrm{IC}_{50}$ value of $0.20 \mu \mathrm{g} / \mathrm{mL}$. Moreover, this class of capsules is further expected to be applied in various biomedical applications, such as theranostic nanomedicine, and 


\section{WILEY-VCH}

multidrug co-delivery. Given the versatility of MPN materials, it is plausible that the properties of these capsules can be further tailored; these include size, shape and surface chemistry for the study of biodistribution and tumor targeting. This approach to fabricate versatile and robust drug-loaded MPN capsules may open up new possibilities for exploring carrier systems in biomedical applications.
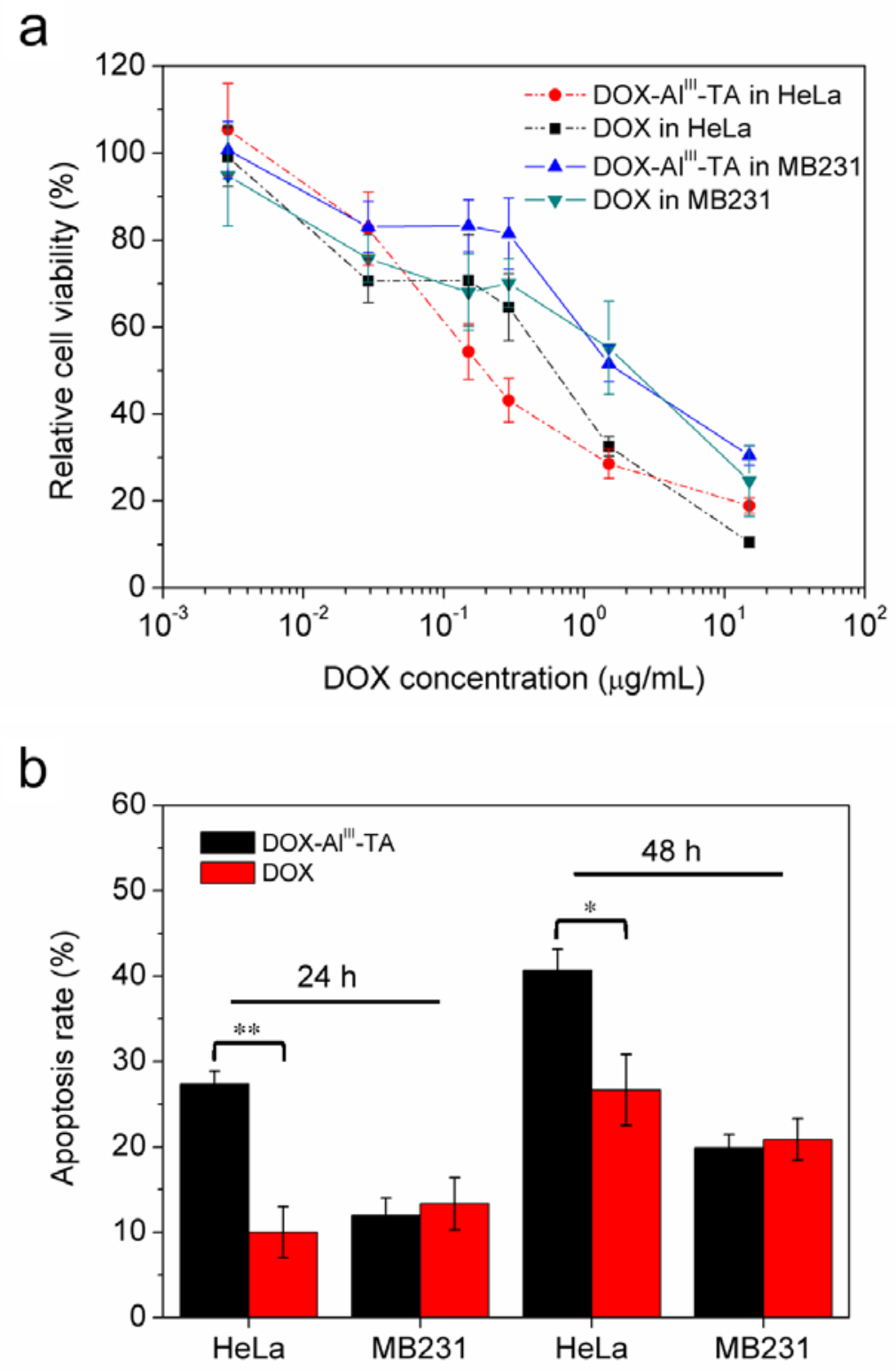

Figure 4. a) Cytotoxicity of DOX-Al ${ }^{\mathrm{III}}$-TA capsules and free $\mathrm{DOX}$ as a function of DOX concentration evaluated by MTT assay after $48 \mathrm{~h}$ incubation. The cell viability of untreated cells was normalized as $100 \%$. Data represent mean \pm SD $(n=4)$. b) Percentage of apoptotic cell HeLa and MB231 cells after treatment with DOX-Al ${ }^{\mathrm{III}}-\mathrm{TA}$ or DOX at different dose for $48 \mathrm{~h}$. All data represent mean $\pm \mathrm{SD}\left(\mathrm{n}=3\right.$, Student's t-test, $\left.* \mathrm{P}<0.05,{ }^{*} \mathrm{P}<0.01\right)$. 


\section{WILEY-VCH}

\section{Experimental Section}

Experimental details in preparation and characterization of drug-loaded MPN capsules, capsule degradation and in vitro DOX release, intracellular drug delivery and cell viability analysis are described in supporting information.

\section{Supporting Information}

Supporting Information is available from the Wiley Online Library or from the author.

\section{Acknowledgements}

This research was conducted and funded by the Australian Research Council Centre of Excellence in Convergent Bio-Nano Science and Technology (project number CE140100036). This work was supported by the Australian Research Council under the Australian Laureate Fellowship (FL120100030) and Discovery Project (DP0877360) schemes. The authors acknowledge Benjamin Hibbs (Advanced Fluorescence Imaging Platform, The University of Melbourne) for assistance with super-resolution microscopy study and Qiong Dai for help with flow cytometry analysis. The authors acknowledge Martin van Koeverden for helpful discussions.

Received: ((will be filled in by the editorial staff))

Revised: ((will be filled in by the editorial staff)) Published online: ((will be filled in by the editorial staff))

[1] D. Morelli, S. Menard, M. I. Colnaghi, A. Balsari, Cancer Res. 1996, 56, 2082.

[2] D. D. Von Hoff, M. W. Layard, P. Basa, H. L. Davis, Jr., A. L. Von Hoff, M. Rozencweig, F. M. Muggia, Ann. Intern. Med. 1979, 91, 710.

[3] M. E. Davis, Z. Chen, D. M. Shin, Nat. Rev. Drug Discov. 2008, 7, 771.

[4] X. Hu, X. Jing, Expert Opin. Drug Deliv. 2009, 6, 1079.

[5] H. Sun, F. Meng, R. Cheng, C. Deng, Z. Zhong, Expert Opin. Drug Deliv. 2013, 10, 1109.

[6] J. H. Park, S. Lee, J.-H. Kim, K. Park, K. Kim, I. C. Kwon, Prog. Polym. Sci. 2008, 33, 113.

[7] F. H. Meng, W. E. Hennink, Z. Zhong, Biomaterials 2009, 30, 2180.

[8] M. Marguet, C. Bonduelle, S. Lecommandoux, Chem. Soc. Rev. 2013, 42, 512.

[9] L. Meng, X. Zhang, Q. Lu, Z. Fei, P. J. Dyson, Biomaterials 2012, 33, 1689.

[10] M. Adeli, R. Soleyman, Z. Beiranvand, F. Madani, Chem. Soc. Rev. 2013, 42, 5231.

[11] Q. He, J. Shi, Adv. Mater. 2014, 26, 391.

[12] P. Yang, S. Gai, J. Lin, Chem. Soc. Rev. 2012, 41, 3679.

[13] L. Mei, Z. Zhang, L. Zhao, L. Huang, X. L. Yang, J. Tang, S. S. Feng, Adv. Drug Delivery. Rev. 2013, 65, 880. 


\section{WILEY-VCH}

[14] R. Ameloot, F. Vermoortele, W. Vanhove, M. B. Roeffaers, B. F. Sels, D. E. De Vos, Nat. Chem. 2011, 3, 382.

[15] S. De Koker, R. Hoogenboom, B. G. De Geest, Chem. Soc. Rev. 2012, 41, 2867.

[16] A. L. Becker, A. P. Johnston, F. Caruso, Small 2010, 6, 1836.

[17] H. Ai, Adv. Drug Deliv. Rev. 2011, 63, 772.

[18] B. G. De Geest, N. N. Sanders, G. B. Sukhorukov, J. Demeester, S. C. De Smedt, Chem. Soc. Rev. 2007, 36, 636.

[19] L. E. Gerweck, K. Seetharaman, Cancer Res. 1996, 56, 1194.

[20] J. R. Casey, S. Grinstein, J. Orlowski, Nat. Rev. Mol. Cell Biol. 2010, 11, 50.

[21] I. F. Tannock, D. Rotin, Cancer Res. 1989, 49, 4373.

[22] H. Ejima, J. J. Richardson, F. Caruso, Polym. J. 2014, 46, 452.

[23] H. Ejima, J. J. Richardson, K. Liang, J. P. Best, M. P. van Koeverden, G. K. Such, J. Cui, F. Caruso, Science 2013, 341, 154.

[24] J. Guo, Y. Ping, H. Ejima, K. Alt, M. Meissner, J. J. Richardson, Y. Yan, K. Peter, D. von Elverfeldt, C. E. Hagemeyer, F. Caruso, Angew Chem. Int. Ed. 2014, 53, 5546.

[25] H. Imai, N. Tochimoto, Y. Nishino, Y. Takezawa, Y. Oaki, Cryst. Growth Des. 2012, 12, 876.

[26] D. V. Volodkin, A. I. Petrov, M. Prevot, G. B. Sukhorukov, Langmuir 2004, 20, 3398.

[27] W. Tong, W. Dong, C. Gao, H. Möhwald, J. Phys. Chem. B. 2005, 109, 13159.

[28] J. Shi, C. Du, Y. Wang, S. Cao, Macromol. Biosci. 2013, 13, 494.

[29] X. Yang, X. Zhang, Z. Liu, Y. Ma, Y. Huang, Y. Chen, J. Phys. Chem. C 2008, 112, 17554.

[30] R. Venkatesan, A. Pichaimani, K. Hari, P. K. Balasubramanian, J. Kulandaivel, K. Premkumar, J. Mater. Chem. B 2013, 1, 1010.

[31] A. J. Khopade, F. Caruso, Biomacromolecules 2002, 3, 1154.

[32] C. E. Brubaker, H. Kissler, L.-J. Wang, D. B. Kaufman, P. B. Messersmith, Biomaterials 2010, 31, 420.

[33] Y. Lee, H. J. Chung, S. Yeo, C.-H. Ahn, H. Lee, P. B. Messersmith, T. G. Park, Soft Matter 2010, 6, 977.

[34] N. Slabbert, in Plant Polyphenols, Vol. 59 (Eds: R. Hemingway, P. Laks), Springer US, 1992, 421.

[35] J. Su, F. Chen, V. L. Cryns, P. B. Messersmith, J. Am. Chem. Soc. 2011, 133, 11850.

[36] C. Sanson, C. Schatz, J. F. Le Meins, A. Soum, J. Thevenot, E. Garanger, S. Lecommandoux, J. Control. Release 2010, 147, 428.

[37] R. Liu, B. He, D. Li, Y. Lai, J. Chang, J. Z. Tang, Z. Gu, Int. J. Nanomedicine 2012, 7, 4433.

[38] M. Oishi, H. Hayashi, M. Iijima, Y. Nagasaki, J. Mater. Chem. 2007, 17, 3720.

[39] J. Lotem, M. Peled-Kamar, Y. Groner, L. Sachs, Proc. Natl. Acad. Sci. U.S.A. 1996, 93, 9166.

[40] S. W. Lowe, S. Bodis, A. McClatchey, L. Remington, H. E. Ruley, D. E. Fisher, D. E. Housman, T. Jacks, Science 1994, 266, 807. 


\section{WILEY-VCH}

\section{Graphical Entry}

A new class of pH-responsive capsules based on metal-phenolic networks (MPNs) for anticancer drug loading, delivery and release is reported. The fabrication of drug-loaded MPN capsules, which is based on the formation of coordination complexes between natural polyphenols and metal ions over a drug-coated template, represents a rapid strategy to engineer robust and versatile drug delivery carriers.

Keyword Templated assembly, hybrid organic-inorganic materials, controlled release, chemotherapeutics, stimuli-responsive, coordination complex

Y. Ping, J. Guo, H. Ejima, X. Chen, J. J. Richardson, H. Sun and F. Caruso*

pH-Responsive Capsules Engineered from Metal-Phenolic Networks for Anticancer Drug Delivery

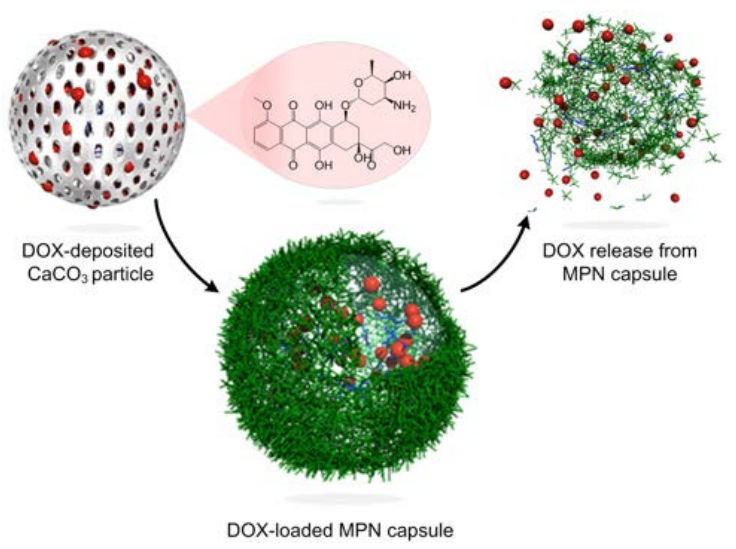

